\title{
GREEN SYNTHESIS, CHARACTERIZATION AND ANTIMICROBIAL ACTIVITY OF SILVER NANOPARTICLES (AgNPs) FROM MAIZE (ZEA MAYS L.)
}

\author{
EREN, A. ${ }^{1 *}-$ BARAN, M. F. $^{2}$ \\ ${ }^{I}$ Department of Crops and Animal Production, Kiziltepe Vocational Training High School \\ Artuklu University, 47200 Mardin, Turkey \\ ${ }^{2}$ Medical Laboratory Techniques, Vocational Higher School of Healthcare Studies, Artuklu \\ University Mardin, 47200 Mardin, Turkey \\ (e-mail: mfiratbaran@gmail.com) \\ *Corresponding author \\ e-mail: abdullaheren@artuklu.edu.tr
}

(Received $4^{\text {th }}$ Dec 2018; accepted $27^{\text {th }}$ Feb 2019)

\begin{abstract}
In recent years, the biosynthesis (green synthesis) of metal nanoparticles such as silver nanoparticles (AgNPs) have become one of the safest, most cost-effective and environmentally friendly approaches. In this study, AgNPs were synthesized using maize (Zea mays L.) leaves. For the characterization of synthesized AgNPs different techniques were used, such as X-ray diffraction spectroscopy (XRD), Ultraviolet visible (UV-Vis) spectroscopy, transmission electron microscopy (TEM), Energy dispersive X-ray spectroscopy (EDX), Fourier-transformed infrared spectroscopy (FT-IR) and Thermal gravimetric and Differential thermal analysis (TGA-DTA). The XRD results showed that AgNPs had a mean diameter of $12.63 \mathrm{~nm}$ and a crystal-like appearance. In addition, antimicrobial activities of synthesized AgNPs were evaluated using 3 different antibiotics against Gram-negative Escherichia coli and Gram-positive Staphylococcus aureus bacteria and Candida albicans yeast. Antifungal activity of AgNPs with antibiotics has been observed to be better than the antibiotics against Gram-positive and Gramnegative bacteria. The minimum inhibitory concentrations were found to be $0.084,0.337$ and $0.021 \mathrm{mg} \mathrm{mL}^{-}$ ${ }^{1}$ for Escherichia coli, Staphylococcus aureus, and Candida albicans, respectively. The results revealed that AgNPs synthesized from maize leaf extract have antibacterial activity against Gram-negative Escherichia coli, Gram-positive Staphylococcus aureus and antifungal activity against Candida albicans yeast, and that the produced AgNPs could be used in the production of biomedical products and in the pharmaceutical industry.
\end{abstract}

Keywords: antimicrobial activity, green AgNPs, Escherichia coli, Staphylococcus aureus, Candida albicans

\section{Introduction}

Scientific research and applications of nanotechnology have increased rapidly in recent years. The properties of nanoparticles such as durability, high diffusion, and versatile chemical and biological activities have gained importance in technological applications (Nabila and Kannabiran, 2018). Metal nanoparticle synthesis researches have been increasing in number due to the potential applications in nanotechnology (Isaac et al., 2013). Nanoparticles are used in many industrial fields, especially in electrical, biomedical, automotive and chemical sectors due to their superior properties (Gürmen et al., 2008). Generally, nanoparticles are defined as particles smaller than 100 nanometers (nm) (Kreyling et al., 2006).

The green technology used in the production of metal nanoparticles has become popular in recent years because of its being rapid, easy, cheap, sustainable and ecofriendly. Green synthesis, as an alternative to physical and chemical synthesis studies 
for the production of AgNPs, is considered as an environmentally friendly and costeffective method used by researchers from many different fields of science (Banerjee et al., 2014; Nartop, 2016; Majeed et al., 2018). In the biological synthesis of nanoparticles, organisms such as bacteria, fungi, seaweeds, plants, yeasts, and viruses are used (Khan et al., 2018). Among these organisms, plants are considered to be the most preferred organisms when they are evaluated in terms of cost and availability. In literature, antibacterial activity of metal or metal oxide such as zinc oxide nanoparticles (ZnO-NPs) has received significant interest worldwide (Gunalan et al., 2012). The most synthesized metal nanoparticles are copper $(\mathrm{Cu})$, silver $(\mathrm{Ag})$, gold $(\mathrm{Au})$, zinc $(\mathrm{Zn})$, nickel (Ni) and palladium (Pd). Edison and Sethuraman (2012) stated that the synthesized $\mathrm{Ag}$ and $\mathrm{Au}$ nanoparticles by Magnolia kobus, Diospyros kaki, Ficus benghalensis and Citrus lemon plant extracts are stable products. In studies with plants, the greatest phytochemicals, tannins, gallic acid, and gallate esters can be easily hydrolyzed (Swamy et al., 2015; Nabila and Kannabiran, 2018).

In this study, the plant extract obtained from maize plant leaves was used for the reduction of $\mathrm{Ag}^{+}$ions which are the basis of the synthesis of $\mathrm{AgNPs}$ to $\mathrm{Ag}^{0}$ ions. Antimicrobial activity was evaluated by characterization of the obtained AgNPs. The green technology used in the synthesis of AgNPs in this study is cheaper, easier and faster than other applications.

\section{Materials and Method}

The plant extract used in the study was obtained from maize (Zea mays L.) plant. In the synthesis method, silver nitrate $\left(\mathrm{AgNO}_{3}\right.$, purity $\left.99.8 \%\right)$ was used. The used antibiotics (Fluconazole, Vancomycin, and Colistin) were obtained commercially.

\section{Preparation of plant extract}

Collected maize leaves from Mardin region in Turkey were washed with deionized water, then dried under room conditions and afterward 50 grams of the ground samples were taken and boiled at $85^{\circ} \mathrm{C}$ with $500 \mathrm{~mL}$ of distilled water. After the formation of the extract, the sample was left to cool until reached the room temperature. Subsequently, filtration was performed using Whatman filter paper and the filtered extract was stored at $4^{\circ} \mathrm{C}$.

\section{Synthesis of nanoparticle}

In general, the formation of AgNPs is determined by spectrophotometric measurements based on color change and time (Swamy et al., 2015; Jamdagni et al., 2016). A $1 \mathrm{mM} \mathrm{AgNO}_{3}$ aqueous solution was used for the synthesis of AgNPs. In total, $125 \mathrm{~mL}$ of maize plant leaf extract and $500 \mathrm{~mL}$ of $\mathrm{AgNO}_{3}$ solution were put into the reaction at room temperature in a $1000 \mathrm{~mL}$ flask. At the end of 40 minutes, the reduction of silver ions resulted in the change of light-colored $\mathrm{Ag}^{+}$ions to dark brown and the maximum absorbance value was determined at $461 \mathrm{~nm}$ wavelength by UV-Vis spectroscopy. The resulting dark solution was centrifuged at $6000 \mathrm{rpm}$ for $20 \mathrm{~min}$ to remove the upper liquid phase and the remaining solid was washed seven times with distilled water. The obtained AgNPs were kept in a laboratory oven at $75^{\circ} \mathrm{C}$ for 24 hours and then left to dry and stored until the application of characterization tests. 


\section{Characterization techniques}

Ultraviolet spectra of synthesized AgNPs were determined in the UV-1601 220V Shimadzu spectrophotometer in the wavelength range of $350-800 \mathrm{~nm}$. Size and morphology of AgNPs were determined using EVO 40 LEQ scanning electron microscopy. The crystal structures of AgNPs were analyzed with RadB-DMAX II computer-controlled $\mathrm{X}$-ray diffractometer in the $3^{\circ} \leq 2 \theta \geq 79^{\circ}$ range. SEM-energy dispersive X-ray (SEM-EDX) spectroscopy was used to verify the presence of AgNPs in the elemental composition. FT-IR analysis was performed in the 4000-400 $\mathrm{cm}^{-1}$ range with the Perkin Elmer spectrum one-brand device to determine which functional groups were involved in the reduction of plant extracts. Decomposition temperatures of AgNPs were determined by thermal gravimetric analysis at a constant heating rate (Shimadzu TGA-50) at $25^{\circ} \mathrm{C} \min ^{-1}\left(25^{\circ} \mathrm{C}-900^{\circ} \mathrm{C}\right)$ under the nitrogen atmosphere.

The evaluation of XRD phase and crystal structure analysis of green synthesized AgNPs is shown in Figure 1. The reflections (111), (200), (220) and (311) of the spherical structures of the AgNPs were calculated in the XRD analysis by $2 \theta\left(38.01^{\circ}, 45.83^{\circ}, 64.29^{\circ}\right.$ and $\left.77.34^{\circ}\right)$ values. It was determined that AgNPs have elemental $\left(\mathrm{Ag}^{\circ}\right)$ and spherical crystalline structure. The mean crystal size was calculated as $12.63 \mathrm{~nm}$ with the following Debye-Scherrer equation (Kanipandian and Thirumurugan, 2014):

$$
D=K \lambda /(\beta \cos \theta)
$$

In the equation, $D$ is particle size $(\mathrm{nm}), \mathrm{K}$ is constant $(0.90), \lambda$ is wavelength $\mathrm{X}$-ray $\left(1.5406^{\circ} \mathrm{A}\right), \beta$ is half of the highest peak value (FWHM) and $\theta$ is the refractive angle.

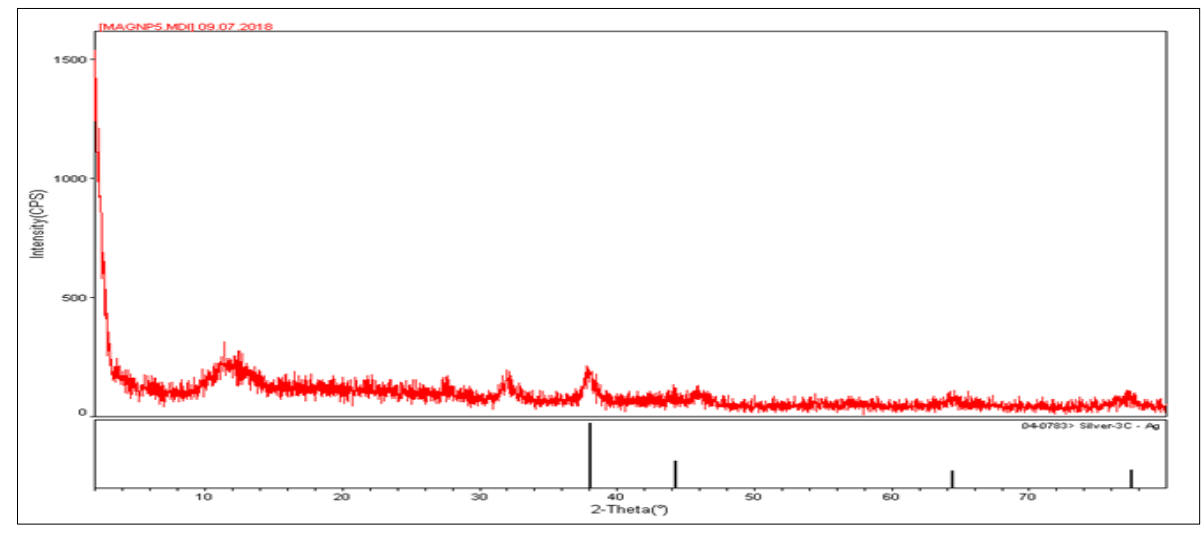

Figure 1. XRD spectra of green method synthesized AgNPs

\section{Antimicrobial activity of silver nanoparticles}

The antimicrobial assays were performed by the minimum inhibitory concentration (MIC) method (Wang et al., 2017). For this purpose, AgNPs were incubated overnight with Gram-positive (S. aureus ATCC 29213) and Gram-negative (E. coli ATCC 25922) bacterial and fungal ( $C$. albicans) strains. Experiments were performed by the microdilution method and the predetermined medium was added to 96-well microplates. Following the preparation of a dilution series at adjusted concentrations, AgNP solutions were added on these dilutions. 
Then, the solutions including a certain amount of microorganism were prepared according to $0.5 \mathrm{McFarland}$ standard, added onto the samples and the samples were incubated at $37^{\circ} \mathrm{C}$ overnight. After incubation, the lowest concentration without growth was determined as MIC (Nadaroglu et al., 2017; Abinaya et al., 2018). All experiments were repeated with four replicates per treatment.

\section{Results and discussion}

\section{Analysis of ultraviolet-visible spectroscopy}

The formation of AgNPs with samples taken at 5, 10, 15, 20, 25, 30, 35 and 40 minutes was observed with UV-Vis spectroscopy analysis. The synthesized AgNPs showed a sharp plasmon resonance at a maximum of $461.25 \mathrm{~nm}$ (Fig. 2). Similarly, AlQahtani et al. (2017) determined the surface plasmon resonance of AgNPs at $468.5 \mathrm{~nm}$. Furthermore, the absorption spectra of AgNPs in the reaction medium were indicated to be in the maximum absorption in the range of 425 to $475 \mathrm{~nm}$ due to surface plasmon resonance of AgNPs (Banerjee et al., 2014).
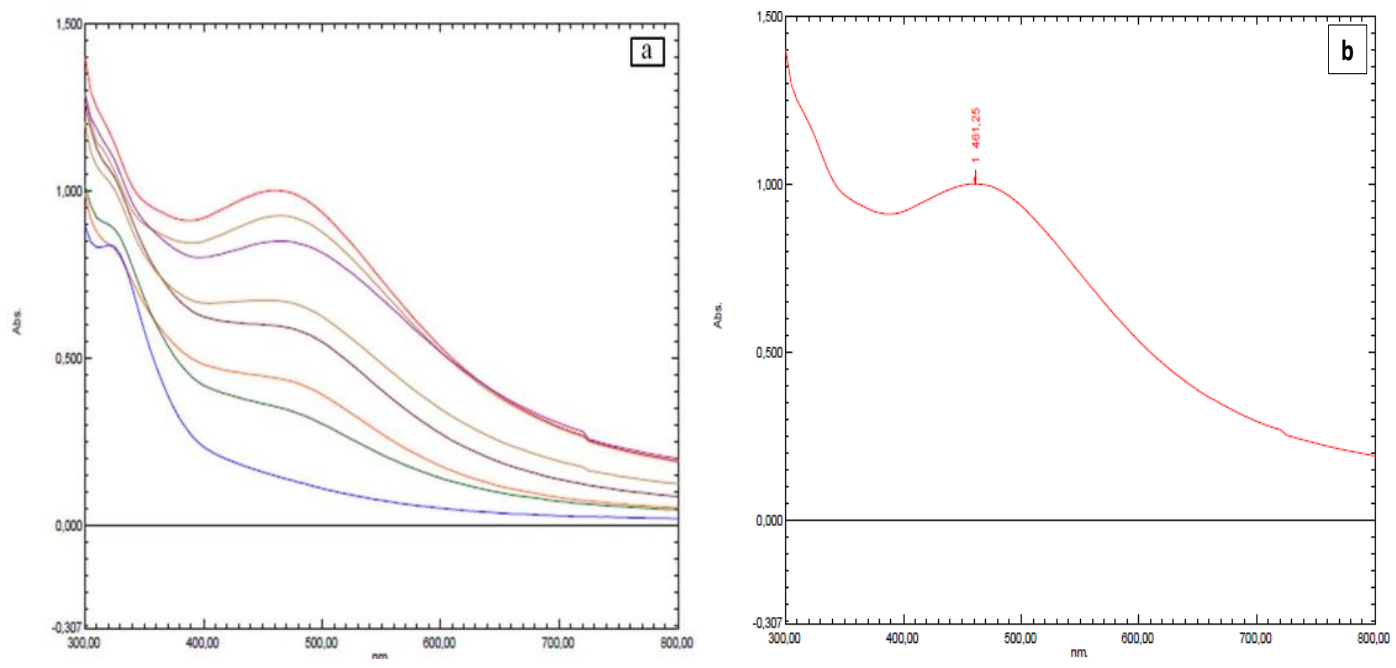

Figure 2. a) Time-dependent formation of AgNPs in UV -Vis spectroscopy, b) Maximum absorbance value of synthesized AgNP in UV-Vis Spectrophotometer

\section{Fourier-transformed infrared spectroscopy analysis}

The infrared spectrum in Figure 3. provides information about the functional groups of the synthesized AgNPs from maize leaf extract. The strong asymmetric flexural band of 3326.99-3321.54 $\mathrm{cm}^{-1}$ belongs to the -OH functional group on the leaf extract surface of the maize shifted due to the interaction between the extract and the silver metal. A frequency shifting of about $5 \mathrm{~cm}^{-1}$ occurred at the peaks around $3326.99 \mathrm{~cm}^{-1}$. In the strong asymmetric stretch band at 2103-2106 $\mathrm{cm}^{-1}$, a $3 \mathrm{~cm}^{-1}$ frequency shifting occurred between $\mathrm{C} \equiv \mathrm{C}$ and $\mathrm{C} \equiv \mathrm{N}$ groups. It was found that there was no considerable shifting in the 1636.29-1636.01 $\mathrm{cm}^{-1}$ band of the C-C groups belonging to the Amide I band and C$\mathrm{N}$ functional groups and also the binding occurred on these three functional groups.

Shah et al. (2017) produced AgNPs by the interaction of $\mathrm{AgNO}_{3}$ with an aqueous solution containing Xanthorrhoea glauca leaf extract and identified the peaks of carboxy 
and amide groups at 1642, 1556, 1536. They reported that the AgNPs demonstrated varying degrees of antibacterial activity against Escherichia coli and Staphylococcus epidermis, with Staphylococcus epidermis showing a larger zone of inhibition (11 mm).

The FT-IR spectrum measurements of AgNPs synthesized by Huang et al. (2007) showed the presence of five dense bands at 3422, 2922, 1629, 1381 and $651 \mathrm{~cm}^{-1}$. It has also been stated that the maximum shifting was at $3422 \mathrm{~cm}^{-1}$. In another study, it has been reported that the $-\mathrm{OH}$ stretch at $3430 \mathrm{~cm}^{-1}$ belongs to the functional groups of $-\mathrm{C}-\mathrm{N}$ (peptide bone) at $2083 \mathrm{~cm}^{-1}$ and C-C at $1641 \mathrm{~cm}^{-1}$ and also the binding takes place on these two functional groups (Singh et al., 2017).

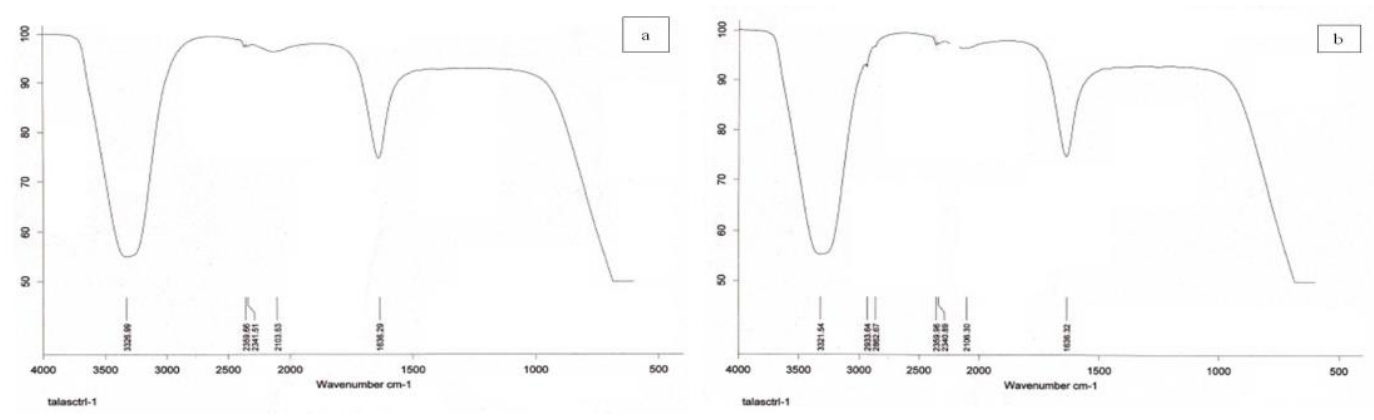

Figure 3. a) UV-Vis spectrum of plant extract, $b$ ) UV-Vis spectrum of synthesized AgNPs

\section{Scanning electron microscopy and energy dispersive X-ray spectroscopy analysis of silver nanoparticles}

Morphological characteristics of AgNPs obtained from leaf extract of maize were investigated with scanning electron microscopy (SEM). The results clearly demonstrated the presence of spherically shaped AgNPs below $100 \mathrm{~nm}$ (Fig. 4).

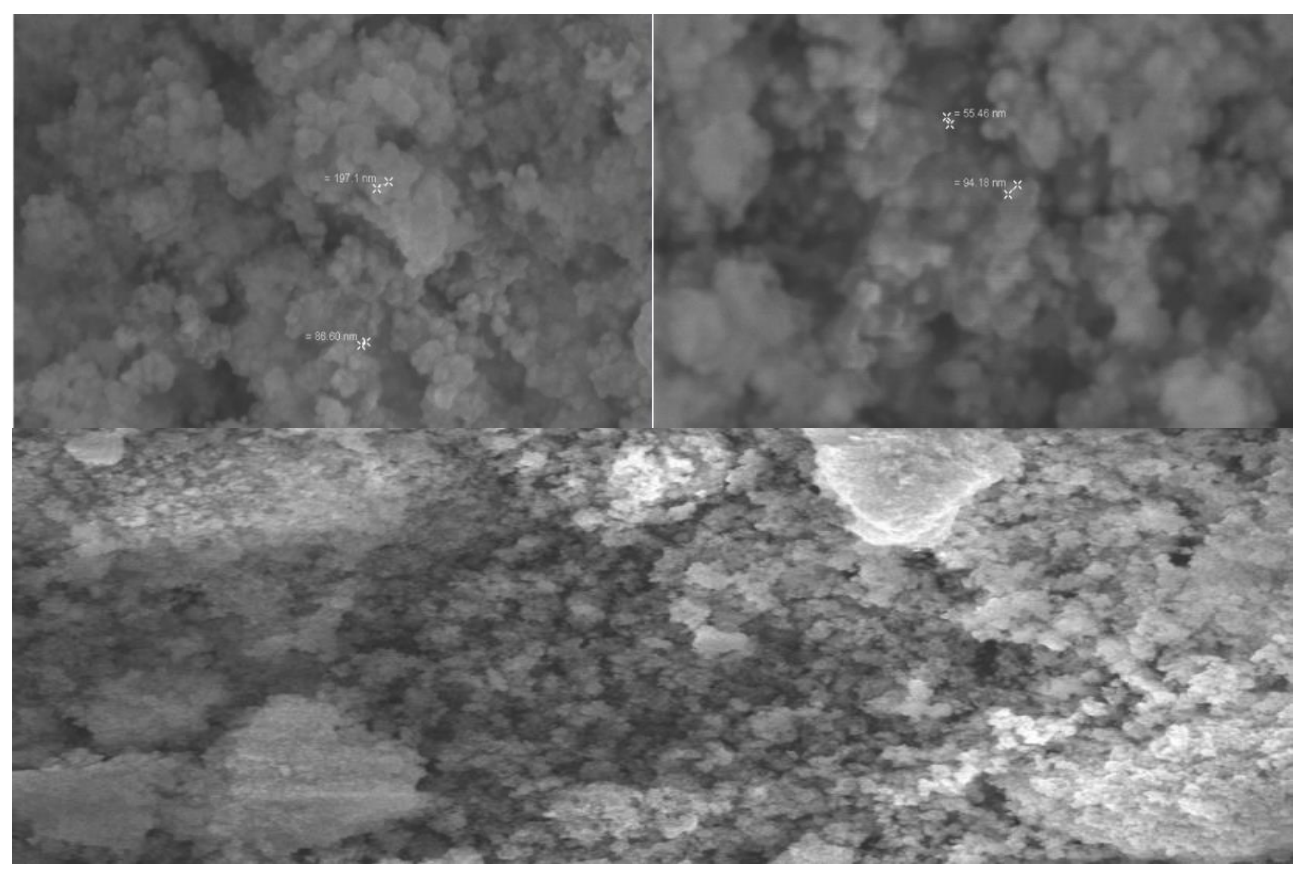

Figure 4. Images of SEM analysis of synthesized AgNPs 
Nanoparticles produced with green synthesis by Phanjom et al. (2012) from Myrica esculenta resulted with different morphologies ranging from $45 \mathrm{~nm}$ to $80 \mathrm{~nm}$ and the Ag nanoparticles obtained from Ziziphus nummularia plant leaves by Khan et al. (2016) had spherical and homogenous shapes with diameters ranging between 30 and 85 $\mathrm{nm}$. In similar SEM analysis studies, the size and morphological characteristics of AgNP are consistent with the results of this study (Swamy et al., 2015).

When the obtained results of this study were compared to the results of the study belonging to Kotakadi et al. (2013), it was seen that AgNPs have a spherical shape and the diameters of AgNPs varied between 27 and $50 \mathrm{~nm}$. As can be seen in Figure 5, the energy-dispersed spectra of AgNPs obtained from the SEM-EDX analysis revealed pure silver particles.
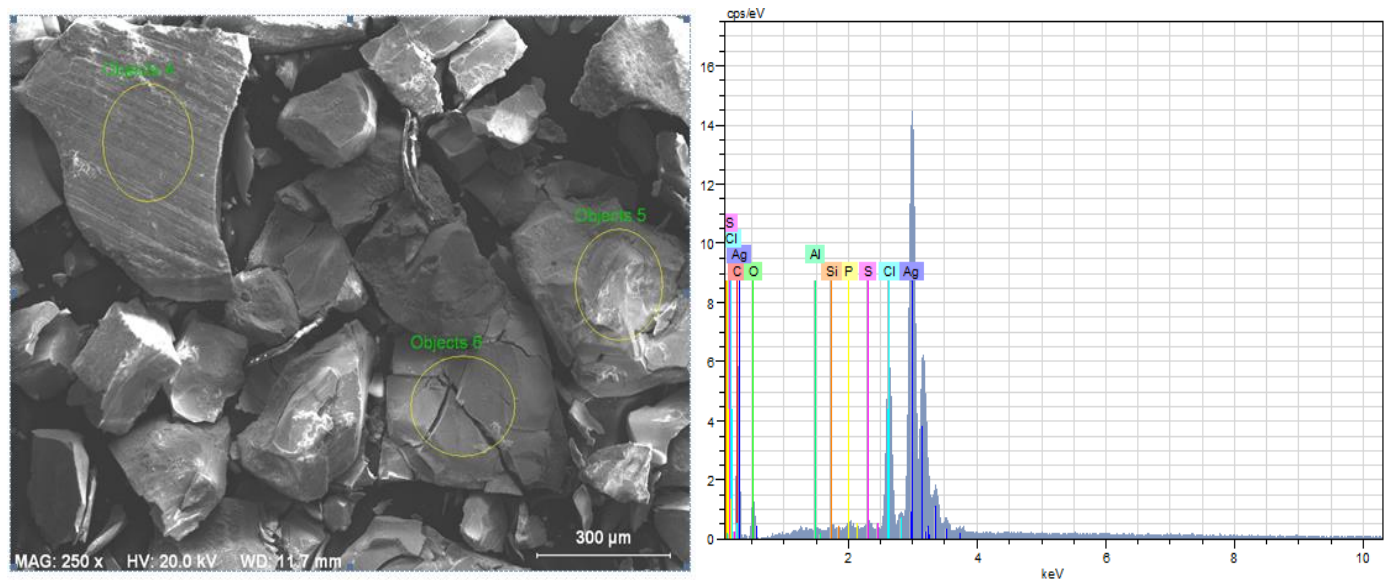

Figure 5. SEM-EDX spectrum of AgNPS

\section{Thermal gravimetric and differential thermal analysis results}

The TGA and DTA analyses of the nanoparticles prepared by green synthesis were evaluated between $25-900^{\circ} \mathrm{C}$ with a heating rate of $10^{\circ} \mathrm{C} \mathrm{min}^{-1}$ and a flow rate of $20 \mathrm{~mL} \mathrm{~min}^{-1}$ in $\mathrm{N}_{2}$ (g) atmosphere. The TGA curve indicates the mass loss due to thermal decomposition and the DTA curve shows the maximum decomposition temperature at each stage of the degradation (Baran, 2017).

As can be seen in Figure 6, the loss of mass at $37-100^{\circ} \mathrm{C}$ was caused by moisture, the loss of mass at $186-309^{\circ} \mathrm{C}$ was due to the cellulosic materials, and the loss of mass at 309$610^{\circ} \mathrm{C}$ was caused by phytochemicals from a plant extract. Finally, the substance was completely degraded at $610-900^{\circ} \mathrm{C}$. The TGA data revealed that the mass loss of AgNPs synthesized in the study was between $50-800^{\circ} \mathrm{C}$. In a similar study, when the TGA curve of AgNPs was examined, it was reported that there was a constant mass loss in the 50$800^{\circ} \mathrm{C}$ temperature range and this loss was due to the desorption of bioorganic compounds (Ali et al., 2015).

\section{Antimicrobial assays of synthesized silver nanoparticles}

In this study, the antimicrobial effect of AgNPs obtained from maize leaf was investigated by MIC method. The possible antibacterial effects of AgNPs on Gramnegative E. coli ATCC 25922 and Gram-positive S. aureus ATCC 29213 strains and antifungal activities on $C$. albicans were investigated. MIC values of AgNP and $1 \mathrm{mM}$ 
silver nitrate were determined. The antimicrobial effect results of the produced AgNPs on E. coli ATCC 25922, S. aureus ATCC 29213 bacteria and C. albicans yeast were obtained as $0.084,0.337$ and $0.021 \mu \mathrm{g} \mathrm{mL}^{-1}$, respectively (Table 1).
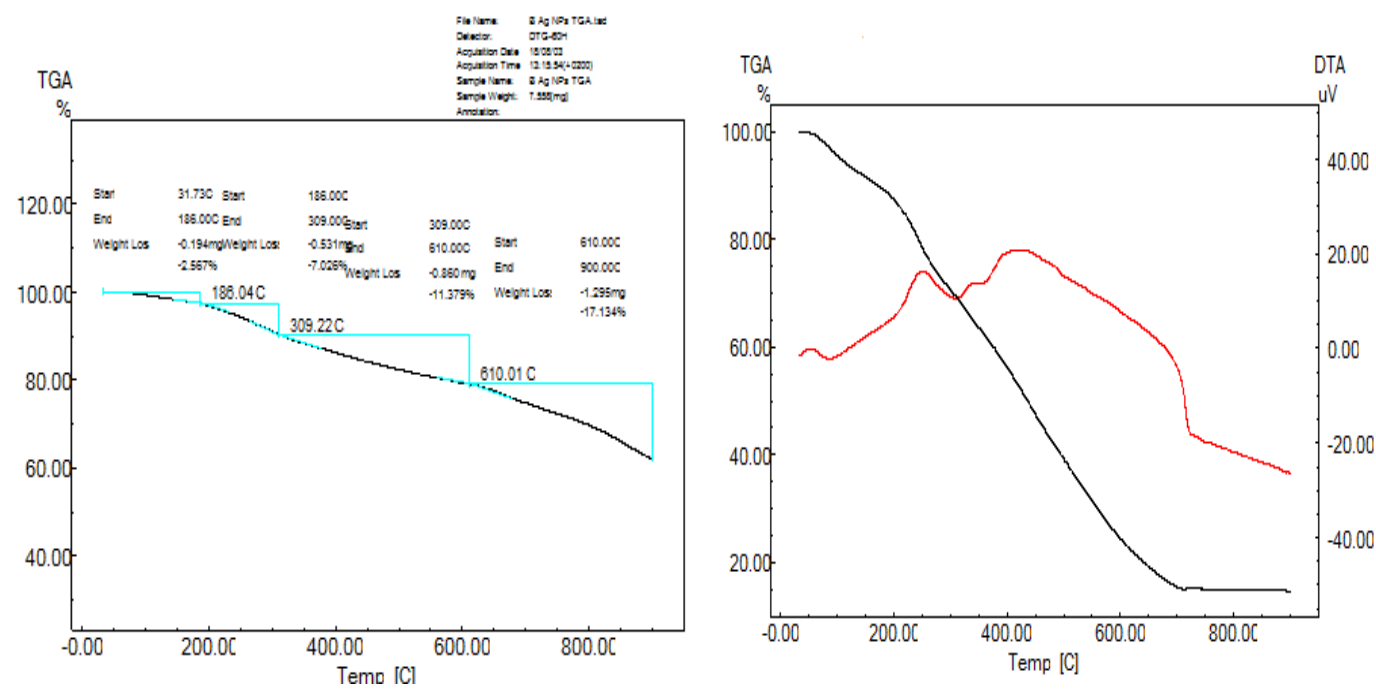

Figure 6. TGA-DTA analysis result of the synthesized silver nanoparticle

Table 1. Minimum inhibitory concentration (MIC) values of AgNPs ( $\left.\mu g \mathrm{~mL}^{-1}\right)$

\begin{tabular}{c|c|c|c}
\hline Organism & AgNP & Silver Nitrate & Antibiotic \\
\hline S. aureus ATCC 29213 & 0.337 & 0.500 & 0.500 \\
C. albicans & 0.021 & 0.500 & 0.500 \\
E. coli ATCC25922 & 0.084 & 1.000 & 0.125 \\
\hline
\end{tabular}

Table 1 shows that AgNPs exhibit a more pronounced activity than silver nitrate. Wang et al. (2017) reported that AgNPs synthesized from green coffee grains showed excellent antibacterial activity against both Gram-negative and Gram-positive bacteria. Tippayawat et al. (2016) stated that the minimum inhibition concentration of AgNPs which they synthesized from Aloe vera plants was effective.

In another study, the nanoparticles synthesized with $S$. potatorum leaf extract were shown to be effective against on MDR human pathogenic bacteria namely, S. aureus and K. pneumonia (Kagithoju et al., 2015). Similar observations were reported on Boswellia ovalifoliolata and Shorea tumbuggai (Savithramma et al., 2011). Therefore, this study shows that the biosynthetic AgNPs have antimicrobial activity.

\section{Conclusions and recommendations}

Nowadays, different antimicrobial agents are being developed to be used on bacteria and yeasts which are resistant to antibiotics that still are in use in medicine and pharmacy. Therefore, many researchers have concentrated their studies on this field. In this study, the synthesis of AgNPs was performed by using maize plant extract. It has been determined that the synthesized AgNPs by maize leaf extract have a spherical structure. The synthesized AgNPs were characterized by UV, XRD, SEM-EDX, TGA-DTA and FT-IR methods. It is known that green synthesis is a cheap, simple and environmentally 
friendly method and the biosynthesis of AgNPs is an alternative method to the chemical synthesis method. Furthermore, AgNPs produced by biosynthesis demonstrated a good antimicrobial effect on different strains.

Green-synthesized AgNPs will open up a new field for the production of pharmaceutical products, the biomedical and industrial products in the pharmaceutical industry.

\section{REFERENCES}

[1] Abinaya, M., Vaseeharan, B., Divya, M., Sharmili, A., Govindarajan, M., Alharbi, N. S., Kadaikunnan, S., Khaled, M., Benelli, G. (2018): Bacterial exopolysaccharide (EPS)coated $\mathrm{ZnO}$ nanoparticles showed high antibiofilm activity and larvicidal toxicity against malaria and Zika virus vectors. - Journal of Trace Elements in Medicine and Biology 45: 93-103.

[2] Ali, K., Ahmed, B., Dwivedi, S., Saquib, Q., Al-Khedhairy, A. A., Musarrat, J. (2015): Microwave accelerated green synthesis of stable silver nanoparticles with Eucalyptus globulus leaf extract and their antibacterial and antibiofilm activity on clinical isolates. PloS one 10(7): 1-20.

[3] AlQahtani, F. S., AlShebly, M. M., Govindarajan, M., Senthilmurugan, S., Vijayan, P., Benelli, G. (2017): Green and facile biosynthesis of silver nanocomposites using the aqueous extract of Rubus ellipticus leaves: toxicity and oviposition deterrent activity against Zika virus, malaria and filariasis mosquito vectors. - Journal of Asia-Pacific Entomology 20(1): 157-164.

[4] Banerjee, P., Satapathy, M., Mukhopahayay, A., Das, P. (2014): Leaf extract mediated green synthesis of silver nanoparticles from widely available Indian plants: synthesis, characterization, antimicrobial property and toxicity analysis. - Bioresources and Bioprocessing 1(1): 3 .

[5] Baran, M. F. (2017): Biosorption of some toxic metals in water. - PhD Thesis, Dicle University, Institute of Science and Technology, Diyarbakır.

[6] Edison, T. J. I., Sethuraman, M. G. (2012): Instant green synthesis of silver nanoparticles using Terminalia chebula fruit extract and evaluation of their catalytic activity on reduction of methylene blue. - Process Biochemistry 47(9): 1351-1357.

[7] Gunalan, S., Sivaraj, R., Rajendran, V. (2012): Green synthesized ZnO nanoparticles against bacterial and fungal pathogens. - Progress in Natural Science: Materials International 22(6): 693-700.

[8] Gürmen, S., Ebin, B., İtü, M. (2008): Nanoparticles and production methods-1. Metallurgical Journal 150: 31-38.

[9] Huang, J., Li, Q., Sun, D., Lu, Y., Su, Y., Yang, X., Wang, H., Wang, Y., Shao, W., He, N., Hong, J., Chen, C. (2007): Biosynthesis of silver and gold nanoparticles by novel sundried Cinnamomum camphora leaf. - Nanotechnology 18(10): 105104.

[10] Isaac, R. S., Sakthivel, G., Murthy, C. H. (2013): Green synthesis of gold and silver nanoparticles using Averrhoa bilimbi fruit extract. - Journal of Nanotechnology, Article ID: 906592.

[11] Jamdagni, P., Khatri, P., Rana, J. S. (2016): Green synthesis of zinc oxide nanoparticles using flower extract of Nyctanthes arbor-tristis and their antifungal activity. - Journal of King Saud University-Science.

[12] Kagithoju, S., Godishala, V., Nanna, R. S. (2015): Eco-friendly and green synthesis of silver nanoparticles using leaf extract of Strychnos potatorum Linn. F. and their bactericidal activities. - 3 Biotech 5(5): 709-714.

[13] Kanipandian, N., Thirumurugan, R. (2014): A feasible approach to phyto-mediated synthesis of silver nanoparticles using industrial crop Gossypium hirsutum (cotton) extract 
as stabilizing agent and assessment of its in vitro biomedical potential. - Industrial Crops and Products 55: 1-10.

[14] Khan, F. A., Zahoor, M., Jalal, A., Rahman, A. U. (2016): Green synthesis of silver nanoparticles by using Ziziphus nummularia leaves aqueous extract and their biological activities. - Journal of Nanomaterials 21, Article ID: 8026843.

[15] Khan, A. U., Yuan, Q., Khan, Z. U. H., Ahmad, A., Khan, F. U., Tahir, K., Ullah, S. (2018): An eco-benign synthesis of AgNPs using aqueous extract of Longan fruit peel: Antiproliferative response against human breast cancer cell line MCF-7, antioxidant and photocatalytic deprivation of methylene blue. - Journal of Photochemistry and Photobiology B: Biology 183: 367-373.

[16] Kotakadi, V. S., Rao, Y. S., Gaddam, S. A., Prasad, T. N. V. K. V., Reddy, A. V., Gopal, D. S. (2013): Simple and rapid biosynthesis of stable silver nanoparticles using dried leaves of Catharanthus roseus. Linn. G. Donn and its antimicrobial activity. - Colloids and Surfaces B: Biointerfaces 105: 194-198.

[17] Kreyling, W. G., Semmler-Behnke, M., Moller, W. (2006): Health implications of nanoparticles. - Journal of Nanoparticle Research 8(5): 543-562.

[18] Majeed, A., Ullah, W., Anwar, A. W., Shuaib, A., Ilyas, U., Khalid, P., Ali, S. (2018): Costeffective biosynthesis of silver nanoparticles using different organs of plants and their antimicrobial applications: A review. - Materials Technology 33(5): 313-320.

[19] Nabila, M. I., Kannabiran, K. (2018): Biosynthesis, characterization and antibacterial activity of copper oxide nanoparticles (CuO NPs) from actinomycetes. - Biocatalysis and Agricultural Biotechnology 15: 56-62.

[20] Nadaroglu, H., Cicek, S., Gungor, A. A. (2017): Removing Trypan blue dye using nanoZn modified Luffa sponge. - Spectrochimica Acta Part A: Molecular and Biomolecular Spectroscopy 172: 2-8.

[21] Nartop, P. (2016): Use of biosynthetic silver nanoparticles in the surface sterilization of Pyracantha coccinea stem explants. - Pamukkale University Journal of Engineering Sciences 23(6): 759-761.

[22] Phanjom, P., Zoremi, E., Mazumder, J., Saha, M., Baruah, S. B. (2012): Green synthesis of silver nanoparticles using leaf extract of Myrica esculenta. - Int J NanoSci Nanotechnol 3: 73-79.

[23] Savithramma, N., Rao, M. L., Devi, P. S. (2011): Evaluation of antibacterial efficacy of biologically synthesized silver nanoparticles using stem barks of Boswellia ovalifoliolata Bal. and Henry and Shorea tumbuggaia Roxb. - Journal of biological sciences 11(1): 3945.

[24] Shah, M., Poinern, G. E. J., Fawcett, D. (2017): Biosynthesis of silver nanoparticles using indigenous Xanthorrhoea glauca leaf extract and their antibacterial activity against Escherichia coli and Staphylococcus epidermis. - International Journal of Research in Medical Sciences 4(7): 2886-2892.

[25] Singh, A. K., Tiwari, R., Kumar, V., Singh, P., Khadim, S. R., Tiwari, A., Asthana, R. K. (2017): Photo-induced biosynthesis of silver nanoparticles from aqueous extract of Dunaliella salina and their anticancer potential. - Journal of Photochemistry and Photobiology B: Biology 166: 202-211.

[26] Swamy, M. K., Akhtar, M. S., Mohanty, S. K., Sinniah, U. R. (2015): Synthesis and characterization of silver nanoparticles using fruit extract of Momordica cymbalaria and assessment of their in vitro antimicrobial, antioxidant and cytotoxicity activities. Spectrochimica Acta Part A: Molecular and Biomolecular Spectroscopy 151: 939-944.

[27] Tippayawat, P., Phromviyo, N., Boueroy, P., Chompoosor, A. (2016): Green synthesis of silver nanoparticles in aloe vera plant extract prepared by a hydrothermal method and their synergistic antibacterial activity. - PeerJ 4: e2589.

[28] Wang, M., Zhang, W., Zheng, X., Zhu, P. (2017): Antibacterial and catalytic activities of biosynthesized silver nanoparticles prepared by using an aqueous extract of green coffee bean as a reducing agent. - RSC Advances 7(20): 12144-12149. 